Chairman A. L. Melander: Mr. R. S. Woglum and M. B. Rounds have sent in a paper which will be read by the Secretary.

\title{
DAYLIGHT ORCHARD FUMIGATION
}

By R. S. Woglum and M. B. Rounds, U. S. Bureau of Entomology

Orchard fumigation of citrus trees in this country has, with few exceptions, been confined strictly to night operations from the earliest days of its commercial adoption. During hot weather trees have not been covered until sundown, but with the advent of cool weather in late autumn, fumigation was frequently started while the sun was still up; and in winter full exposure to gas was sometimes made on cool days. Occasionally a venturesome fumigator attempted daylight work in the winter without regard to temperature and, although temporary success sometimes followed, sooner or later severe injury was experienced and return to the night practice invariably followed.

In 1918 a situation arose in California which necessitated prolongation of the fumigation season well into the winter and an outgrowth of this in Orange County was a large amount of daylight work, in part performed in the bright sunshine at comparatively high winter temperatures. This was carried on without experiencing the severe injury which had always proved a check in former years. One operator in particular was so impressed with the possibilities of daylight work that he practically abandoned night fumigation throughout the season of 1919. The past winter, 1919-20, saw an additional number of outfits fumigating very extensively during the daytime.

A special investigation of daylight fumigation was started by the writers in 1919 with the object of ascertaining the reasons for the greater freedom from injury at the present time with liquid hydrocyanic acid than in former years under the pot and machine methods of generation, and also of determining if a system of daylight fumigation both practical and safe could be developed. Partial results of this investigation are presented herewith.

Prior to 1916 orchard fumigation was performed with a highly heated gas generated in the field. The introduction of liquid hydrocyanic acid was accompanied by a new method of field application which produced a cool gas at the lower part of the tree and resulted in very different diffusion from that of the heated field-generated gas. This was pointed out by the senior writer ${ }^{1}$ who showed that at warm temperatures the scale-kill in the case of pot-generated gas is best toward the top of the tree whereas with liquid hydrocyanic acid it is best toward the bottom. Gas concentration is proportional to scalekill.

\footnotetext{
1 Jour. Econ. Ent., V. 12, No. 1, 1919.
} 
Injury from daylight work is confined largely to the sunward side of the tree and its intensity at different heights is governed in great degree by the concentration of the gas during the exposure. This condition frequently reflects the method of generation, in the case of pot-generated gas the greatest injury being toward the top of the tree, the part of greatest concentration, whereas trees fumigated with liquid hydrocyanic acid usually exhibit injury most severe lower down on the sunward side.

It is well known that at high temperatures hydrocyanic acid is more toxic to plants than at low temperatures. Therefore, a knowledge of heat conditions within the tent at the time of treatment is essential to a correct understanding of its bearing on plant injury. Table I shows the comparative temperatures at different parts of a tented tree in the sunshine at varying periods after covering.

Table I.-Showng the Comparative Temperatoreg at Different Parts or a 12-Ft. Orange Tree Amter Covering with an 8-Ounce Army Duck Text on a Bright Sonshiny Day is Drcember. Rrcords Taken 6 to 10 Inches from thi Cloth

\begin{tabular}{|c|c|c|c|c|}
\hline \multirow{2}{*}{ Time } & \multicolumn{2}{|c|}{ Sunward side (S.) } & \multirow{2}{*}{$\frac{\text { Shade side (N.) }}{\text { Bottom } 4 \text { feet }}$} & \multirow{2}{*}{$\frac{\text { Outside tent }}{\text { Direct sun }}$} \\
\hline & Top 11 feet & Bottom 4 feet & & \\
\hline 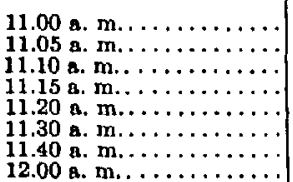 & $\begin{array}{l}69^{\circ} \mathrm{F} . \\
76 \\
82 \\
87 \\
91 \\
92 \\
93 \\
95\end{array}$ & $\begin{array}{l}69^{\circ} \mathrm{F} \\
72 \\
79 \\
82 \\
83 \\
83 \\
83 \\
85\end{array}$ & $\begin{array}{l}66^{\circ} \mathrm{F} \\
68 \\
68 \\
70 \\
71 \\
72 \\
73 \\
74\end{array}$ & $\begin{array}{l}69^{\circ} \mathrm{F} . \\
69 \\
69 \\
70 \\
71 \\
71 \\
72 \\
72\end{array}$ \\
\hline
\end{tabular}

An examination of this table shows that the temperature within the tent on the sunward side rises rapidly for the first 15 or 20 minutes following covering, the increase at the top of the tent after 20 minutes being 20 degrees higher than the outside air, an average that was slightly increased during the last 40 minutes of the exposure. The temperature at 4 feet on the sunward side was much lower than at the top. It is of particular interest to note that the maximum temperature increase on the shaded side of the tree at 4 feet was only 5 degrees greater than the normal increase of the air temperature outside the tent and, as compared with the maximum increase near the top, sunward side, was 21 degrees less than this extreme. Therefore, it is evident that the temperature of a tree covered in the daytime is greatly increased on the sunward side especially at the top although the shaded part shows little increase above the outside air.

Holding in mind that a strong gas is more injurious than a weak one, and also that toxicity increases with the temperature, it is readily seen that in the case of pot-generated gas where the greatest strength 
is toward the top of the tent, which is also the point of the highest temperature, there is concentrated a maximum of influence for injury. Turning to the use of liquid hydrocyanic acid quite the reverse is true. The gas becomes weaker toward the top of the tent, the part of highest temperature, and the most concentrated gas is toward the bottom where the influence of the sunshine is less felt. Between these two factors, temperature and gas concentration, the latter appears to be the more dominant, for as a general rule the greatest injury to trees fumigated in the sunshine with liquid hydrocyanic acid is centered about half way up the tree on the sunward side. In all cases the injury is decidedly less than with pot-generated gas. The shaded side with its more normal temperature and without the sun-influence is seldom modified to any great degree either in point of injury or scalekill over that normal to an equal temperature at night.

\section{Scale-Kill in Different Parts of a Tree Fumigated in the Sunshine}

The scale-kill is by no means uniform throughout a tree fumigated in the sunshine but rather irregular and reflects the effects of varying temperature and gas concentration at the different parts. This is shown in the following table which gives the results based on five trees infested with black scale which were fumigated March 3, 1920, with liquid hydrocyanic acid. The scale was in the rubber stage, approaching maturity, a condition in which they are very difficult to destroy and which require sharp influences to detect distinct differences in mortality. The insects were taken from outside branches and averaged 200 to 500 for each count.

Table II-The Scale-Kill in Difmerent Pahts of 12-Foot Trees Fumionted wimh Liquid Hydroctanic Acid in the Sunghine with a Full Dosmog Schedde for 50 Mindter, March, 1920

\begin{tabular}{|c|c|c|c|}
\hline \multirow{2}{*}{ Tree No. } & \multicolumn{3}{|c|}{ Per cent killed } \\
\hline & $\begin{array}{c}\text { Sunward (S.) } \\
3 \text { to } 6 \text { feet }\end{array}$ & Top (N.) & $\begin{array}{l}\text { Shade (N.) } \\
2 \text { to } 4 \text { feet }\end{array}$ \\
\hline 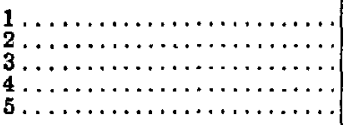 & $\begin{array}{l}75 \\
96 \\
94 \\
75 \\
84\end{array}$ & $\begin{array}{l}36 \\
87 \\
17 \\
11 \\
36\end{array}$ & $\begin{array}{l}47 \\
70 \\
20 \\
14 \\
25\end{array}$ \\
\hline A verage. . . . . . . . . . . . . & 84 & 30 & 27 \\
\hline
\end{tabular}

These results show the scale-kill on the sunward side of the tree at 3 to 6 feet to be greatly superior to that on the shaded side both low down as well as at the top. In fact the mortality on the shaded part

\footnotetext{
${ }^{1}$ JoUr. Econ. ENT., V. 12, No. 5, p. 361.
} 
of the tree averaged less than one-third as high as that at the point of greatest mortality on the sunward side. A large number of other trees which were similarly fumigated showed decidedly increased mortality on the sunward side. The scale-kill at the top of the tree appeared to be modified somewhat by its shape. As a general rule the kill at the top was noticeably superior on the part toward the sun. The sunward part of the top, however, was decidedly inferior to that nearer the bottom on the same side. While the kill at the top, sunward side, was superior to that of all shaded parts of the tree, there appeared to be no constant superiority one way or the other between the top and bottom on the shaded side. Illustrated by an average dome-shaped orange tree 12 feet tall, the highest scale-mortality in sunshine fumigation during the winter is at the periphery of the tree in the direct path of the sun and about 3 to 6 feet above the ground. The mortality appears to decrease in all directions from this point and is lowest on the shaded north side, which is least influenced by temperature changes. The scale-kill in sunshine work at any time at best must be very irregular since it is influenced directly by temperature and this varies in different parts of the tree. Furthermore, the ratio of the temperatures at different parts of a tented tree to each other changes with the position of the sun at different hours of the day as well as its angle to the horizon at different seasons of the year.

\section{The Influence of Tenting Material}

Eight-ounce special U. S. army duck is considered the most, satisfactory gas-holding cloth used in commercial fumigation, and tests by the senior writer have demonstrated its superiority to drills in night fumigation. Tents are frequently dipped in tannin to prevent mildew but it has been determined by experimental night fumigation that this in no way increases their gas-holding quality. Therefore, it was a matter of considerable surprise to ascertain superior kill in sunshine fumigation with tannin-treated drill tents than with eight-ounce army duck.

Tablx III-Showino Conparative Scale-Kill from songhine Fumigation with Liquid Hydrocyanic Acid Under Tannin-Treated 6h-Odnce Drill and Untreated 8-Ounce Duck Tents.

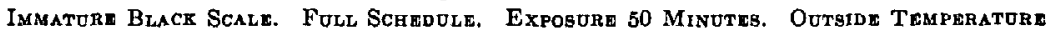
$68^{\circ}-70^{\circ}$, MARCH, 1920

\begin{tabular}{|c|c|c|c|c|}
\hline \multirow{2}{*}{. } & \multirow{2}{*}{ No. trees } & \multicolumn{3}{|c|}{ Per cent killed } \\
\hline & & $\begin{array}{c}\text { Shade (N.) } \\
1-3 \mathrm{ft} .\end{array}$ & $\underset{2-6 \mathrm{ft} .}{\operatorname{Sun}\left(\mathrm{S}_{1}\right)}$ & Top \\
\hline $\begin{array}{l}\text { Tannin-treated drill. } \ldots \ldots \ldots \ldots \ldots \ldots \ldots \ldots \ldots \ldots \ldots \ldots \ldots \ldots \ldots \\
\text { White duck. } \ldots \ldots \ldots \ldots \ldots \ldots \ldots \ldots\end{array}$ & $\begin{array}{l}2 \\
3\end{array}$ & $\begin{array}{l}99.3 \\
92.7\end{array}$ & $\begin{array}{l}99.6 \\
99.5\end{array}$ & 99.2 \\
\hline
\end{tabular}


The above table presents the results of experimental work in whicb five orange trees of equal size infested with immature black scale were fumigated with liquid hydrocyanic acid according to the same dosage schedule and for the same exposure. Two trees were covered with tannin-treated (dark colored) $6 \frac{1}{2}$-ounce drill and three trees were covered with 8-ounce untreated duck. The results of the fumigation show that the dark-colored tents gave the best scale-kill, this superiority being most evident on the north side of the tree. This difference in mortality in favor of dark-colored tents was even more effectively brought out where the maximum scale-kill departed more widely from the point of eradication than for the above trees. For instance, one set of trees given a 30-minute exposure averaged 95 per cent scale-kill on the shaded side of the trees fumigated under dark-colored drill tents but showed only 76 per cent scale-kill at the same position on trees fumigated under untreated duck tents.

This difference in scale-kill between the dark and light tents appeared attributable to the higher temperatures within the former. This condition is shown by the following table in which is recorded the temperature at different points within a tannin-treated drill tent as well as a white army duck tent.

Tagle IV-The Comparative Temperatureg at Different Partg of Two 12-Foot Trxe, One Covered with a 6t-Ounce Tannin-Treated (Dark Colored) Tent and the Other Covered with a Whitu 8-Odnce Afmy Duck Tent. May 18, 1920, 9-10 a. u. Rhconds Made at 10 . Mindte Intervals. Thinmometers 6-8 Inches from Tent

\begin{tabular}{|c|c|c|c|c|c|c|c|c|c|c|c|c|c|c|}
\hline \multirow{2}{*}{ Time } & \multicolumn{2}{|c|}{ Outside temp. } & \multicolumn{3}{|c|}{ Sunward $3 t$ ft. } & \multicolumn{3}{|c|}{ Sunward $11 \mathrm{ft}$. } & \multicolumn{3}{|c|}{ Shade (N.) $3 t \mathrm{ft}$. } & \multicolumn{3}{|c|}{ Middle $3 \mathrm{ft}$. } \\
\hline & Sun & Shade & $\begin{array}{c}\text { Dark } \\
\text { tent }\end{array}$ & $\begin{array}{c}\text { Light } \\
\text { tent }\end{array}$ & Dif. & $\underset{\text { tent }}{\text { Dark }}$ & $\begin{array}{c}\text { Light } \\
\text { tent }\end{array}$ & Dif. & $\begin{array}{c}\text { Dark } \\
\text { tent }\end{array}$ & $\begin{array}{c}\text { Light } \\
\text { tent }\end{array}$ & Dif. & $\begin{array}{c}\text { Dark } \\
\text { tent }\end{array}$ & $\begin{array}{c}\text { Light } \\
\text { tent }\end{array}$ & Dif. \\
\hline $\begin{array}{l}\text { Start...... } \\
10 \min . . . \\
20 \min . . . \\
30 \min . . . \\
40 \min . . . \\
50 \min . . . \\
60 \min . . .\end{array}$ & $\begin{array}{l}82^{\circ} \\
85 \\
85 \\
87 \\
88 \\
86 \\
89\end{array}$ & $\begin{array}{l}78^{\circ} \\
79 \\
80 \\
82 \\
83 \\
85 \\
85\end{array}$ & $\begin{array}{l}90^{\circ} \\
93 \\
95 \\
98 \\
97 \\
99\end{array}$ & $\begin{array}{l}87^{\circ} \\
89 \\
90 \\
91 \\
91 \\
92\end{array}$ & $\begin{array}{l}3^{\circ} \\
4 \\
5 \\
7 \\
6 \\
7\end{array}$ & $\begin{array}{l}97^{\circ} \\
104 \\
108 \\
110 \\
110 \\
112\end{array}$ & $\begin{array}{c}95^{\circ} \\
101 \\
104 \\
106 \\
106 \\
108\end{array}$ & $\begin{array}{l}2^{\circ} \\
3 \\
4 \\
4 \\
4 \\
4\end{array}$ & $\begin{array}{l}84^{\circ} \\
87 \\
80 \\
90 \\
91 \\
92\end{array}$ & $\begin{array}{l}79^{\circ} \\
81 \\
82 \\
83 \\
84 \\
85\end{array}$ & $\begin{array}{l}5^{\circ} \\
6 \\
7 \\
7 \\
7 \\
7\end{array}$ & $\begin{array}{l}83^{\circ} \\
80 \\
88 \\
89 \\
90 \\
91\end{array}$ & $\begin{array}{l}79^{\circ} \\
82 \\
82 \\
83 \\
84 \\
85\end{array}$ & $\begin{array}{l}4^{0} \\
4 \\
6 \\
6 \\
6 \\
6\end{array}$ \\
\hline
\end{tabular}

Not only is the temperature higher at all points within a dark colored tent, especially on the shaded side where the average difference amounts to 6 or 7 degrees, but there appears to be an influence on the gas diffusion due to the heat factor which interferes with its escape through the tenting and this influence is most apparent under the darker tent. So noticeable is this difference in gas retention between the two types of tents that it is readily detected by the smell at the end of a normal exposure. In our experimental work during the winter it was observed that one could stay beneath an 8-ounce untreated duck 
tent with safety and without annoyance at the end of a 50-minute daylight exposure so little gas remained, but on the other hand this was seldom possible beneath the tannin-treated tents especially on the sunward side, because of the greater volume of residual gas. Particularly of interest is the tendency of the gas to remain strongest on the hot sunward side of the tree and to escape more freely from the cooler portions.

As a possible explanation of this situation it can be stated that the sun falling on the tent produces a very rapid rise in temperature, which is greatest immediately beneath the cloth and decreases as the distance away becomes greater. The cyanid gas is cold when entering the tent at the lower and cooler part. As it diffuses with the air and rises the mixture comes in contact with the hotter air on the sunward side but appears to be retarded in escaping from the tent on this side by the very highly heated peripheral layer of air immediately adjacent to the cloth. Dark colored tenting intensifies the temperature of this layer.

Table V-Thmperature Comparigon on Sunward Side of the Peripheral Layer of Air Ingide Two Trees Coverid Regpetively with Light and Dark Colored Tents. Records Taken 11 Fert Agove Ground Onn Hour amter Covering

\begin{tabular}{|c|c|c|c|c|c|}
\hline \multicolumn{3}{|c|}{$\begin{array}{l}\text { Light tent } \\
\text { 8-0s. army duck }\end{array}$} & \multicolumn{3}{|c|}{$\begin{array}{l}\text { Dark tent } \\
\text { Bł-oz. drill }\end{array}$} \\
\hline $\begin{array}{l}\text { Temp. } 6-8 \text { in. } \\
\text { from clath }\end{array}$ & $\begin{array}{l}\text { Temp. immedi- } \\
\text { ately adjacent } \\
\text { cloth }\end{array}$ & Difference & $\begin{array}{l}\text { Temp. 6-8 in. } \\
\text { from cloth }\end{array}$ & $\begin{array}{c}\text { Temp. immedi- } \\
\text { ately adjac- } \\
\text { ent cloth }\end{array}$ & Difference \\
\hline $106^{\circ}$ & $118^{\circ}$ & $12^{\circ}$ & $114^{\circ}$ & $142^{\circ}$ & $28^{\circ}$ \\
\hline
\end{tabular}

The dark colored tent shows the remarkable difference of 28 degrees between the temperature immediately adjacent the cloth and that distant 6 to 8 inches; the white tent only 12 degrees. Records taken simultaneously at $3 \frac{1}{2}$ feet on the shaded side of the tree gave temperatures of 92 and 85 degrees respectively for the dark and light tents. When these latter records are compared with those taken immediately adjacent the cloth on the sunward side there is presented the very great difference of 50 degrees between the extremes of temperature within the tannin-treated tent and 33 degrees within the white tent.

The temperature of the air on the shaded or north side of the tree covered with the white tent almost paralleled that of the outside air and in the case of the dark tent was but 6 to 7 degrees higher. Therefore, the absence of a hot layer of air on the shaded side immediately adjacent to the tent allows the gas to diffuse outward as freely over this area as at night. 


\section{Comparison of Day and Night Fumigation}

The effect of the gas on the scale and the effect on the plant both demand careful attention in a comparison of daylight and night fumigation and one ordinarily acts as a balance on the other in recommending or condemning the practice. From the standpoint of scalekill, night practice can be differentiated from sunshine practice by the comparative results at different parts of the tree, and in the accompanying table is presented such a comparison for experimental work performed against the black scale.

Table VI-Comparibon of Night and Sunghine Fumigation Aganst Immature Blace Scaly, Uging a fold Dosage-Schedule in Marce, 1920. Each Set of Frodreg Ropresents the Average of Five Trees.

\begin{tabular}{|c|c|c|c|c|}
\hline \multirow{2}{*}{ Time } & \multirow{2}{*}{ Temperature } & \multirow{2}{*}{ Exposure } & \multicolumn{2}{|c|}{ Per cent killed } \\
\hline & & & Shade (N.) & $\operatorname{Sun}_{2-5}(\mathrm{~S})$. \\
\hline 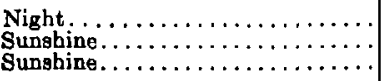 & $\begin{array}{l}46^{\circ} \\
69 \\
71\end{array}$ & $\begin{array}{l}50 \mathrm{~min} . \\
50 \mathrm{~min} . \\
30 \mathrm{~min} .\end{array}$ & $\begin{array}{l}93 \\
95 \\
82\end{array}$ & $\begin{array}{l}94 \\
98 \\
98\end{array}$ \\
\hline
\end{tabular}

A study of this table shows that sunshine work at a temperature of $69^{\circ}$ was decidedly superior to the night fumigation at 46 degrees. This superiority was due unquestionably to temperature differences. Experiments performed by the writers show that in night work better scale-kill occurs at higher temperatures than at low temperatures. The results in night fumigation are quite uniform throughout the bottom of the tree whereas daylight work gives the best kill on the sunward side where the temperature influence is greatest, as previously stated. Additional experiments carried out against mature black scale showed an even greater difference in mortality between night and day work, the superiority always being most outstanding on the sunward side.

Trees with a 30-minute exposure were fumigated in the sunshine simultaneously with those given a 50-minute exposure. These results, which are presented in Table VI, are of interest in showing that on the sunward side the kill is but slightly inferior to that for a 50-minute exposure whereas on the shaded side of the tree it is decidedly inferior, at this point giving an 82 per cent scale-kill against a 95 per cent kill for a 50-minute exposure. Comparing a 30-minute sunshine exposure at 71 degrees with a 50-minute night exposure at 46 degrees, the results of the daylight work are seen to be superior on the south side of the tree but decidedly inferior on the north side. In view of the 
uniformity of results throughout the bottom of a tree fumigated at night, whereas in sunshine work the poorest kill is in the more shaded part which is also usually most severely infested, the figures just presented would appear to show that a 50-minute night exposure at a cool temperature is, under some conditions, superior to a 30 -minute sunshine exposure at a much higher temperature.

The greater effectiveness of daylight fumigation to that at night with the same dosage and exposure is clearly evident. The temperature averages many degrees higher during the day which correspondingly increases insect activity as well as susceptibility to the gas. This superiority is most noticeable on the sunward side of the tree. In this connection it must be noted that the severest infestations of such scales as the black and purple are on the more shaded parts of the tree where the superiority of sunshine work is least apparent. This condition is of primary importance in regulating any reduction of dosage for sunshine work, for to accomplish results with a reduced schedule equivalent to night work such reduction of dosage must be made with regard to the scale-kill on the shaded part of the tree where it is most difficult to destroy. The irregularity of scale-kill is one of the greatest drawbacks to the daylight practice.

\section{Factors Limiting Daylight Work}

Sunshine coming in contact with plants immediately after fumigation and before they have fully recovered their normal physiological activity is a factor of the greatest concern from the standpoint of injury. In fact there appears to be no other meteorological condition which so intensifies plant injury. Therefore, in conducting daylight fumigation one is constantly menaced with a factor of great danger. The effect of the sunshine is modified by its intensity (this depends mainly upon the height of the sun above the horizon and the clearness of the atmosphere), by the physiological condition of the plant, by the concentration of gas and by the length of exposure. Thus in entering the field of daylight fumigation we are entering a field of complex nature. Of these factors the strength of gas, the length of exposure and the temperature or intensity of the sunshine are entirely tangible and necessarily form the basis of daylight fumigation procedure. Any plant will withstand a certain amount of gas under the most severe conditions without injury, and within certain limitations this concentration is safely increased as the length of exposure is decreased. This very point appears to be the keynote to successful daylight fumigation. Night fumigation with dosage schedule $\frac{3}{4}$ and No. $1^{1}$ has been followed with safety for many years with exposures

' Bul. 90, Bur. Ent., U. S. Dept. Agr. 
ranging from 45 minutes to one hour, yet the attempt to transplant these dosages and exposures to daylight fumigation under the potsystem has invariably been disastrous.

It has been explained that the more successful use of liquid hydrocyanic acid than pot-generated gas in daylight work is possible because of differences in diffusion which, in the former case, places a weak gas at the top of the tree, the part of greatest heat. This diffusion, together with possible differences in physical properties of the gas, has appeared to render the transfer of night practice to daylight practice possible with a reasonable degree of safety during the winter months when the trees are in a dormant condition. Especially is this true for lemons to which no particular injury has occurred during the past winter's fumigation.

Throughout the summer and autumn trees are very active and the sunlight intense, both of which render fumigation at this time a very precarious practice. However, fumigation can be done even under the most severe combination of conditions provided the dosage is reduced or the exposure shortened sufficiently to offset their influence. Of course, if the reduction of dosage or exposure necessary to offset the injury factor reduces the scale-kill below commercial requirements the operation is a failure.

Injury from daylight fumigation is characterized by leaf drop, particularly on the sunward side of the tree and in severe cases by bleaching of green fruit. The fruit pit so prevalent in night fumigation is infrequent in daylight work. Ripe fruit does not appear to be affected at all and trees have been observed defoliated without the colored fruit being injured in the least. Bleached fruit, if not too severe, may later recolor and appear unblemished, but severe burns reduce the grade. It is scarcely possible to conduct sunshine fumigation without considerable leaf drop. Therefore, one of the most important considerations in attempting this practice is to determine the amount of foliage that can be dropped without injury to the tree. On this growers are at variance.

The writers have taken many records of fumigation during the active autumn period at temperatures upwards to $80^{\circ} \mathrm{F}$. with exposures averaging 30-40 minutes. Dosages as high as 78 and 89 per cent schedules were used. Such practice was in general very effective against the red and black scales, but the injury to the trees was frequently very severe, and in some cases gave almost complete defoliation. The injury in the early morning and late evening was less intense than during the hottest part of the day. By sharp reduction of the dosage and exposure to offset the increased intensity of the sunshine numerous orchards were fumigated at this active period without 
severe injury, and particularly was this true for lemons, which appear to be far less susceptible to sunshine fumigation than are oranges.

On the other hand parts of orchards would sometimes be greatly injured even with a dosage and exposure in no way severe to the same varieties in the adjoining orchards. Such differences in injury are attributable to varying soil conditions and the physiological condition of trees, and in this we find one of the greatest drawbacks to daylight work, for it appears to intensify injury to trees least resistant to gas to a much greater extent than does night practice.

\section{Conclusions}

The writers have carried on experimental daylight fumigation with liquid hydrocyanic acid from the middle of the active fumigation season in October throughout the winter period. As a result of this work they are convinced that, where practicable, daylight winter fumigation is preferable to night work. At this period the insects are especially difficult to kill on cool nights. Furthermore, the trees are in a dormant condition and can withstand a stronger gas even at temperatures approximating $80^{\circ} \mathrm{F}$. Particular attention should be given to the exposure.

While the data accumulated during the past season shows that an experienced and careful operator with a few tents can by constant manipulation of dosage and exposure practice daylight work during the growing season, especially on lemons, with partial success, such practice in preference to night work cannot be recommended at the present time. Experience has proved that fixed dosages and exposures are the safest guides to effective fumigation and the necessary data has not yet been accumulated to establish this condition for daylight summer and autumn work. In fact there is considerable doubt if a fixed dosage-exposure combination can be developed which is practical under the extreme varieties of daylight weather during the usual fumigation season, a situation which is further emphasized by the widely differing conditions between the hot interior valleys and the cooler, more bumid coastal belt.

Chatrman A. L. Melander: We are now prepared to show you three reels of motion pictures illustrating "Beekeeping in the National Forests," by G. A. Coleman. The pictures were screened by the chairman.

Chairman A. L. Melander: The final part of the program will be concluded by Prof. Trevor Kincaid who will briefly discuss "The Earwig Problem About Seattle." (No report was made of this talk by the Secretary.) 
Chairman A. L. Melander: This concludes the program. The meeting stands adjourned, it being understood that we meet next year with the Pacific Division of the American Association for the Advancement of Science, as we have done this year, the meeting scheduled to be held at San Francisco, Cal.

Meeting adjourned.

E. C. VANDYKE, Secretary.

\section{MEXICAN BEAN BEETLE SITUATION}

By W. E. Hinds, Auburn, Ala.

In the October, 1920, issue of the Journal, pp. 430-431, appears a brief statement regarding the discovery of Epilachna corrupta Muls ${ }^{1}$ in Alabama. Scouting work continued through September and October revealed the species in all, or parts, of thirteen counties. This infested area extends in a northeasterly direction from the eastern part of Tuscaloosa County and the northern part of Bibb County to the Georgia Line at the northeastern part of DeKalb County, Alabama. The area infested covers more than 4,500 square miles.

A special effort was made to secure an emergency appropriation of $\$ 250,000$ from the special session of the Alabama Legislature, which met in September, to begin a campaign for the extermination of the pest in this section. This effort failed as it required a two-thirds vote to carry at a special session. Unfortunately no federal funds are available for such work at this time. With the delay incident to securing federal action there would doubtless be time for the spread of the pest during another season, thereby making the extermination of the species doubly difficult, if not quite impossible.

Meantime field work has been under way in studying the life history and insecticidal control of the bean beetle. Control efforts have proven very ineffective with all materials tested thus far. Arsenicals act primarily as repellents and exert some benefit in this way, but may not prove effective in saving a crop from practically complete destruction. It now appears that quite new materials and probably some new machinery and new methods for their application may be needed to solve this problem of control.

Among the food plants, the common bush snap beans appear to be most severely injured, and the loss is likely to be complete henceforth except for a partial yield from the earliest planted beans. This is almost equally true as regards pole beans and shell beans. Lima beans

\footnotetext{
${ }^{1}$ For several reasons it seems that the common name Mexican bean beetle should be used instead of bean ladybird.
} 